\title{
Gamificação e o processo de ensino: questões propostas ao ensino de Matemática
}

\author{
Gamification and the teaching process: proposed questions to teaching Mathematics \\ Gamificación y proceso de enseñanza: supuestos sobre la enseñanza de las Matemáticas
}

Recebido: 10/12/2021 | Revisado: 15/12/2021 | Aceito: 18/12/2021 | Publicado: 02/01/2022

Lucas Alves Lima
ORCID: https://orcid.org/0000-0002-4310-8674
Instituto Federal de Educação, Ciência e Tecnologia do Ceará, Brasil
E-mail: lucasalvespalmes99@ gmail.com
Francisco Jucivânio Félix de Sousa
ORCID: https://orcid.org/0000-0002-0011-6690
Universidade do Vale do Taquari, Brasil
E-mail: jucivanio.felix@ ifce.edu.br
Claudelí Mistura
ORCID: https://orcid.org/0000-0002-4445-7825
Universidade do Vale do Taquari, Brasil
E-mail: claumistura@gmail.com
Silvana Neumann Martins
ORCID: https://orcid.org/0000-0003-1944-3760
Universidade do Vale do Taquari, Brasil
E-mail: smartins@univates.br
José Claudio Del Pino
ORCID: https://orcid.org/0000-0002-8321-9774
Universidade do Vale do Taquari, Brasil
E-mail: delpinojc@yahoo.com.br

\section{Resumo}

Este estudo tem como objetivo discutir o processo de gamificação e suas contribuições no ensino de matemática. Trata-se de uma pesquisa bibliográfica com produções científicas publicadas entre os anos de 2015 e 2020 , embasando a descrição e reflexão de tais estudos. Os resultados apontam que diante de um público jovem inserido nas tecnologias digitais, em que os games representam um dos segmentos de maior preferência desse público há uma necessidade de contribuições de práticas pedagógicas no ensino da matemática por meio do processo da gamificação, contemplando a realidade vivenciada por esses jovens na atualidade. Nesse sentido, a gamificação vem se mostrando cada vez mais eficaz e eficiente ao ensino e à aprendizagem na matemática desses jovens no contexto educacional. Portanto, destaca-se o quanto a gamificação contribui significativamente ao ensino da matemática, mas apresenta algumas dificuldades que ainda necessitam serem enfrentadas pelos professores quando é utilizada em sala de aula.

Palavras-chave: Gamificação; Matemática; Ensino de matemática; Processo de aprendizagem.

\begin{abstract}
This study aims to discuss the gamification process and its contributions to mathematics teaching. This is a bibliographical research with scientific productions published between the years 2015 to 2020, supporting the description and reflection of such studies. The results show that, in view of a young audience inserted in digital technologies, in which games represent one of the most preferred segments of this audience, there is a need for contributions of pedagogical practices in the teaching of mathematics through the gamification process, contemplating the experienced reality by these young people today. In this sense, gamification has shown itself to be increasingly effective and efficient in teaching and learning mathematics for these young people in the educational context. Therefore, it is highlighted how much gamification contributes significantly to the teaching of mathematics, but it presents some difficulties that still need to be faced by teachers when it is used in the classroom.
\end{abstract}

Keywords: Gamification; Mathematics; Teaching of mathematics; Learning process.

\section{Resumen}

Este estudio tiene como objetivo discutir el proceso de gamificación y sus contribuciones a la enseñanza de las matemáticas. Se trata de una investigación bibliográfica con producciones científicas publicadas entre los años 2015 a 2020, que sustenta la descripción y reflexión de dichos estudios. Los resultados muestran que, ante una audiencia joven insertada en las tecnologías digitales, en la que los juegos representan uno de los segmentos más preferidos de esta audiencia, existe la necesidad de aportes de las prácticas pedagógicas en la enseñanza de las matemáticas a través del proceso de gamificación, contemplando la realidad vivida por estos jóvenes hoy. En este sentido, la gamificación se ha mostrado cada vez más eficaz y eficiente en la enseñanza y el aprendizaje de las matemáticas para estos jóvenes en el contexto educativo. Por lo tanto, se resalta cuánto contribuye significativamente la gamificación a la enseñanza 
de las matemáticas, pero presenta algunas dificultades que aún deben enfrentar los docentes cuando se utiliza en el aula.

Palabras clave: Gamificación; Matemáticas; Enseñanza de las matemáticas; Proceso de aprendizaje.

\section{Introdução}

$\mathrm{Na}$ atualidade, pode-se observar o quanto os meios tecnológicos fazem parte do cotidiano das pessoas. O uso do celular e dos computadores não se restringe a fazer uma ligação ou editar algum documento, mas tornou-se um passatempo ou, até mesmo, uma atividade de lazer. Diante disso, temos as crianças e os jovens como um dos grupos de pessoas que estão cada dia mais inseridas nesse mundo digital.

Na pesquisa realizada pela TIC Kids Online Brasil - $2019^{1}$ evidencia-se as seguintes informações: $89 \%$ dos jovens de nove a 17 anos são usuários de internet; o smartphone é o principal meio de acesso com 95\% de utilização; 58\% têm esse dispositivo como forma exclusiva de acesso; cerca de 57\% usam para jogar e ficar conectados com outros jogadores. Já em outra pesquisa realizada em 2019 pela Game Brasil $^{2}$, 66,3\% dos brasileiros utilizam jogos eletrônicos, sendo apontado, também, que 83\% usam smartphone para jogar. Dessa forma, percebe-se o quanto esses meios tecnológicos estão presentes na vida das pessoas, fazendo parte, principalmente, da vida do público infanto juvenil brasileiro. Nesse sentido, cada vez mais essas tecnologias vêm se tornando uma realidade dentro da sala de aula e no âmbito educacional.

Assim, compreende-se que o uso da tecnologia dentro do ambiente escolar impacta não só a rotina dos alunos em sala de aula, mas também dos professores que, cada vez mais, vêm enfrentando dificuldades para lidar com uma geração cada vez mais digital. Diante do exposto, tem-se como desafio atrair a atenção dos estudantes para o que está sendo abordado, surgindo o seguinte questionamento: de que modo podemos deter a atenção desses jovens?

Nesse cenário da revolução digital, existem duas realidades distintas: de um lado, o estudante cada vez mais mergulhado nas tecnologias digitais; e do outro, encontram-se as práticas pedagógicas voltadas para um modelo de ensino tradicional. Nessa perspectiva, Tolomei (2017) afirma que quando se vivencia a realidade da geração atual e o modelo de ensino presenciado nas escolas brasileiras, por sua vez provoca determinada distância entre os envolvidos no processo de ensino e de aprendizagem. Dessa forma, evidencia-se que a atual forma de ensino desinteressa ao estudante, pois as informações são abordadas de maneira genérica e descontextualizada com o ambiente de ensino.

Diante disso, o modelo tradicional de ensino está se mostrando cada vez mais obsoleto para as demandas da educação atual, de modo que Esquivel (2017) fala que "[...] sendo assim, o ensino tradicional, sem recursos digitais e a aula puramente expositiva estão se tornando cada vez menos interessantes para estes estudantes, cuja vida está imersa em tecnologia de última geração". (p. 12).

Ao analisar os índices do Sistema de Avaliação da Educação Básica (SAEB) dos estudantes na disciplina de matemática percebe-se o quanto essa afirmação é impactante e desafiadora, pois de acordo com dados de 2019 da plataforma $Q e d u^{3}, 47 \%$ dos alunos do $5^{\circ}$ ano do ensino fundamental aprenderam o essencial na competência de resolução de problemas matemáticos. Esse dado fica ainda mais preocupante quando se compara ao $9^{\circ}$ ano do ensino fundamental e ao $3^{\circ}$ ano do ensino médio, em que $18 \%$ e $5 \%$, respectivamente, a competência é exercida.

Desse modo, afirma-se o quanto os estudantes apresentam dificuldades na disciplina de matemática. Com isso, considera-se urgente a abordagem de novas práticas de ensino para a sala de aula para que essas possam tornar a matemática mais atrativa e fazer do aluno não um ouvinte, como no ensino tradicional, mas como o protagonista no processo de aprendizagem.

\footnotetext{
${ }^{1}$ Disponível em: https://cetic.br/pt/pesquisa/kids-online/indicadores/. Acesso em: 05 maio 2021.

${ }^{2}$ Disponível em: https://forbes.com.br/colunas/2019/06/mais-da-metade-dos-brasileiros-joga-games-eletronicos/. Acesso em: 05 maio 2021.

3 https://www.qedu.org.br/
} 
Avila et al (2017), em pesquisa realizada com docentes da área de Ciências da natureza e Matemática, no estado do Rio Grande do Sul, da rede privada de ensino relatam que os professores possuem dificuldade em compor estratégias que superem o modelo tradicional e as dificuldades enfrentadas, além disso, o currículo proposto, necessita deixar de ser fragmentado e isolado, deve-se priorizar os discentes na investigação de amplos contextos e possibilitar a integração e interação entre as diferentes disciplinas curriculares existentes.

Santos e Magedanz (2018) corroboram que "São pequenos detalhes que podem contribuir na obtenção máxima de benefícios intermediados pelas metodologias na formação profissional dos alunos.” (pp. 69). Se faz necessário, criar possibilidades diferenciadas das que já se vem utilizando, para estimular o engajamento, a responsabilização e cooperação mútua entre discentes e docentes, no processo de ensino e aprendizagem.

Diversas propostas didáticas vêm sendo apresentadas para o ensino da matemática com intuito de melhorar o rendimento dos alunos e atrair seus olhares para a disciplina, dentre as quais pode-se citar a história da matemática; o uso da informática; a modelagem matemática; e a resolução de problemas.

Nesse sentido, a utilização da gamificação no ensino pode ser considerada um potencial que contempla, de maneira interessante, o público que está presente nas escolas, pois como abordado nos próximos tópicos, a gamificação usa aspectos de um determinado jogo para que se possa melhorar o rendimento de indivíduos em determinadas atividades. Diante disso, o diálogo do processo da gamificação com as práticas pedagógicas, podem contribuir diretamente na qualidade do ensino da matemática, além de evocar por mudanças nas aulas e ampliar as possibilidades para o ensino.

No intuito de discutir a importância de estratégias complementares para o ensino da matemática, levando em conta os principais fatores que influenciam a geração atual, compreende-se o quanto os estudantes necessitam ser instigados e motivados em sala aula, pois são jovens que estão cada vez mais inseridos e atraídos pelas tecnologias digitais. Nesse sentido, a gamificação pode ser uma aliada a essas tecnologias.

Este estudo tem como objetivo discutir o processo de gamificação e suas contribuições no ensino de matemática. Além disso iremos descrever os principais aspectos da gamificação, o que irá possibilitar identificar possíveis subsídios aos processos de ensino e de aprendizagem para a disciplina de matemática.

\section{A Gamificação e os Conceitos Presentes na Literatura}

O termo gamificação é algo relativamente novo, porém, Fardo (2013) pontua que a palavra em si foi introduzida na indústria das mídias digitais em 2008, começando a ganhar mais relevância a partir do ano de 2010. Desse modo, os autores em destaque dessa área, tais como: Karl Kapp, dentre seus livros temos "The gamification of learning and instruction: gamebased methods and strategies for training and education", publicado em 2012; e Gabe Zichermann, das obras de maior destaque são a "The gamification revolution: how leaders leverage game mechanics to crush the competition", publicada em 2013 junto com a autora Joselin Linder, e a obra "Gamification by Design", do ano de 2011, com o autor Christopher Cunningham. Além desses autores, existem outros que abordam a gamificação, como também outras obras sobre os jogos eletrônicos em sala de aula.

Nessa perspectiva, Gomes (2017) coloca que Kapp define a gamificação como o uso dos elementos dos jogos para motivar, envolver pessoas, promover a aprendizagem e resolver problemas. Enquanto Esquivel (2017), destaca que a gamificação não é originalmente uma proposta educacional, de modo que ele apresenta exemplos da mesma fora desse contexto, mas sim aplicativos Foursquare e Waze. Nessa perspectiva, se questiona: o que a gamificação se propõe a fazer em sala de aula? Para Fardo (2013): 
[...] como estratégia aplicável aos processos de ensino e aprendizagem nas escolas ou em qualquer outro ambiente de aprendizagem, é utilizar um conjunto de elementos comumente encontrados na maioria dos games e aplicá-los nesses processos, com o intuito de gerar níveis semelhantes de envolvimento e dedicação daqueles que os games normalmente conseguem gerar. (Fardo, 2013, pp. 65).

Diante disso, qual seria os elementos que a gamificação explora quando aplicada em sala de aula? Gomes (2017) e Fardo (2013) apontam em seus estudos que os elementos destacados por Karl Kapp mais usados na educação são: objetivo, regras, tempo, conflito, competição, cooperação, feedback, níveis de dificuldade, abstração da realidade e criação de história.

Nesse sentido, Fardo (2013) define esses elementos da seguinte maneira: o objetivo em um jogo é a meta que o sujeito deve alcançar; as regras vão controlar as ações dos jogadores durante a realização do jogo; o conflito é colocado como o momento em que o jogador tem que superar um desafio ou um adversário; na competição o jogador vai se dedicar a melhorar o seu desempenho no jogo; em contrapartida, na cooperação os jogadores terão um objetivo em comum, que será bom para todo o grupo.

Ainda, o autor define o feedback como a resposta que o jogo manda para o jogador, a qual pode mudar a forma como o mesmo encara e se comporta no jogo; a narrativa é colocada como um elemento que tem função muito importante nos games, pois é nesse elemento que a ações do jogador vão acontecer - nesse recurso a atividade pode ser fortalecida quando aplicada na gamificação; a recompensa é outro importante elemento do jogo, pois na gamificação ela tem como objetivo incentivar as motivações intrínseca ${ }^{4}$ e extrínseca ${ }^{5}$. Por fim, Fardo (2013) destaca que:

Para fazer uso da gamificação, deve-se pensar nela como uma caixa de ferramentas, onde estão dispostos os elementos dos games. Em cada situação, pode-se utilizar um número diferente de elementos, mas, para isso, deve-se conhecê-los, suas funções, e como irão interagir dentro do sistema que será proposto. (Fardo, 2013, pp.59).

Nessa perspectiva, nos próximos tópicos serão abordadas reflexões sobre os trabalhos selecionados em nossas pesquisas bibliográficas. Foi dada mais importância aos resultados e às realizações das pesquisas feitas pelos autores. Os dois primeiros trabalhos são artigos científicos, o primeiro é uma abordagem mais geral da gamificação na educação e o segundo traz a gamificação aliada às tecnologias digitais no ensino da matemática; os dois últimos são dissertações de mestrado, em que a primeira apresenta uma aplicação da gamificação em uma escola de ensino fundamental e a última faz uma abordagem da gamificação com as teorias das situações didáticas.

\section{Procedimentos Metodológicos}

Este estudo foi desenvolvido por meio de uma Revisão Narrativa da Literatura. A RNL é considerada uma revisão bibliográfica, possibilitando conhecimento amplo sobre determinado assunto com o uso de determinadas fontes norteadoras, tais como: artigos científicos, livros, sites, manuais, teses, dissertações, entre outros (Sousa et al., 2019).

Para compor o corpus amostral do estudo utilizou-se os seguintes critérios de inclusão: produções científicas nacionais com temas que abordam a gamificação no ensino da matemática na educação de modo geral; recorte temporal entre os anos de 2015 a 2020. E como critérios de exclusão: produções científicas que não estavam disponíveis de modo gratuito e na íntegra mesmo após a tentativas de buscas diretamente na fonte de divulgação (periódico, Biblioteca Virtual em Saúde ou no portal da Coordenação de Aperfeiçoamento de Pessoal de Nível Superior (CAPES).

\footnotetext{
${ }^{4}$ Fardo (2013) a define como sendo a situação em que o sujeito faz determinada tarefa ou expõe certo comportamento por causa de fatores internos como orgulho e prazer, dentre outros.

${ }^{5}$ Fardo (2013) a define como sendo a situação em que o sujeito faz uma atividade ou expõe um certo comportamento com objetivo de adquirir uma recompensa.
} 
Nesse sentido, a primeira etapa ocorreu pela realização da busca das produções científicas no Catálogo de Teses e Dissertações da CAPES, no Google Acadêmico e na Biblioteca Digital Brasileira de Teses e Dissertações (BDTD). O período para o desenvolvimento deste estudo foi de outubro de 2020 a maio de 2021.

A estratégia de busca utilizada para a realização deste estudo foi a seguinte: "gamificação and ensino and matemática and educação", com o uso do operador booleano entre as palavras-chaves, em ambas as buscas. Na busca inicial foram encontrados os seguintes resultados: 33464 produções no Catálogo de Teses e Dissertações; 15 na BDTD; e 3390 no Google Acadêmico.

Após a realização da busca e aplicação dos critérios de inclusão do estudo, foram selecionadas 20 produções científicas, das quais nove eram teses e dissertações e 11, artigos. Essas produções foram salvas e procedeu-se a leitura dos resumos, em seguida, verificou-se que somente quatro produções se relacionavam aos objetivos delineados para o estudo, produções com foco na utilização da gamificação e ao ensino de Matemática, sendo realizada a leitura na íntegra para o presente estudo. As características dessas, apresentam-se na Tabela 1.

Tabela 1: Produções científicas incluídas no estudo.

\begin{tabular}{|c|c|c|c|c|c|}
\hline $\begin{array}{l}\text { Tipo de } \\
\text { produção }\end{array}$ & \multicolumn{2}{|c|}{ Autor(es) } & Título & $\begin{array}{c}\text { Ano de } \\
\text { publicação }\end{array}$ & Procedência do estudo \\
\hline Dissertação & $\begin{array}{l}\text { ESQUIVEL, } \\
\text { da Rosa }\end{array}$ & , Hugo Carlos & $\begin{array}{l}\text { Gamificação no ensino da matemática: uma } \\
\text { experiência no ensino fundamental }\end{array}$ & 2017 & $\begin{array}{l}\text { Rio de Janeiro (ensino com } \\
\text { jogos em uma turma de } 8^{\circ} \\
\text { ano) }\end{array}$ \\
\hline Dissertação & $\begin{array}{l}\text { GOMES, } \\
\text { Santos. }\end{array}$ & Marcelo do & $\begin{array}{l}\text { Gamificação e educação matemática: uma } \\
\text { reflexão pela ótica da teoria das situações } \\
\text { didáticas }\end{array}$ & 2017 & $\begin{array}{l}\text { Pesquisa bibliográfica em } \\
\text { periódicos nacionais e } \\
\text { internacionais. }\end{array}$ \\
\hline Artigo & $\begin{array}{l}\text { TOLOMEI, } \\
\text { Vargas. }\end{array}$ & Bianca & $\begin{array}{l}\text { A gamificação como estratégia de } \\
\text { engajamento e motivação na educação }\end{array}$ & 2017 & $\begin{array}{lll}\text { Revisão Sistemática } & \text { de } \\
\text { Literatura, proveniente } & \text { de } \\
\text { estudos desenvolvidos no } & \text { no } \\
\text { Brasil. } & \end{array}$ \\
\hline Artigo & $\begin{array}{l}\text { BARBOSA, } \\
\text { Ellivelton; } \\
\text { Márcio } \\
\text { CASTRO, } \\
\text { Braga. }\end{array}$ & $\begin{array}{l}\text { Francisco } \\
\text { PONTES, } \\
\text { Matoso; } \\
\text { Juscileide }\end{array}$ & $\begin{array}{l}\text { A utilização da gamificação aliada às } \\
\text { tecnologias digitais no ensino da } \\
\text { matemática: um panorama de pesquisas } \\
\text { brasileiras }\end{array}$ & 2020 & $\begin{array}{lll}\text { Revisão Sistemática } & \text { de } \\
\text { Literatura, proveniente } & \text { de } \\
\text { estudos desenvolvidos no } \\
\text { Brasil. }\end{array}$ \\
\hline
\end{tabular}

Fonte: Autores (2021).

\section{Resultados e Discussão}

A seguir será apresentada a descrição dos principais resultados das produções incluídas no estudo, bem como a discussão com a literatura pertinente da área.

A pesquisa "A gamificação como estratégia de engajamento e motivação na educação" (Tolomei, 2017) é um artigo científico publicado em 2017 pela Revista EAD em Foco, cujo objetivo do trabalho é analisar como a gamificação pode aumentar a participação e a motivação dos estudantes. A metodologia usada pela autora se deu pela pesquisa teórica, de cunho bibliográfico, utilizando para a produção do trabalho autores como Gee (2009), McGonical (2012) e Alves (2015), entre outros.

Tolomei (2017) inicia seu trabalho fazendo uma análise de como o modelo de ensino tradicional torna distante como estudantes vivenciam seu dia a dia e como a escola lida com essa realidade, de modo que fica evidente como esse modelo de ensino ocasiona desinteresse nos estudantes. Após introduzir essas questões, a autora inicia seu estudo definindo e mostrando os principais aspectos e origens dos jogos e da gamificação, interligando esses dois elementos e mostrando suas possíveis potencialidades para a sala de aula. 
Nessa perspectiva, a autora começa a mostrar como os jogos podem contribuir no processo de ensino e aprendizagem, de modo que possam levar estímulo e engajamento para proporcionar interações dos estudantes nas atividades em sala de aula. Assim, Tolomei (2017, p. 149) afirma que:

Dessa forma, a ideia de que o uso de games ou atividades gamificadas favorece o engajamento dos estudantes em atividades escolares tidas por eles como enfadonhas é inevitável, porque o uso dos games pode aproximar o processo de aprendizagem do estudante à sua própria realidade. (Tolomei, 2017, pp. 149).

Desse modo, para a pesquisadora, através do uso dos games e da gamificação os estudantes passam a ver significado no que está sendo exposto, pois o professor trabalhará o conteúdo com algo que faz parte do dia a dia dos estudantes. Outro ponto mostrado são os princípios de aprendizagem que os jogos podem desenvolver, que no caso são identidade, interação, produção, risco, problemas e desafios.

Nessa perspectiva, a autora expõe que apesar de haver uma crise de gerações, a partir da qual temos os estudantes mergulhados nos meios tecnológicos e os professores apresentam determinada dificuldade para ingressar nesse universo, os games são atividade que não estão restritas aos jovens, pois têm conquistado cada vez mais usuários de outras idades. Assim, suas potencialidades podem ser mais exploradas em sala de aula, conforme:

As habilidades aprendidas e praticadas com os jogos são pouco desenvolvidas nas escolas, e talvez por isso os jogos despertam ainda uma sensação ameaçadora no meio educacional. A tradição educacional de transmissão de conhecimento não encontra terreno fértil entre os jovens que, por outro lado, não encontram o conhecimento apenas nas escolas. O conhecimento está disponível em qualquer lugar e a qualquer momento. (Tolomei, 2017, pp. 150).

Dessa forma, a autora expõe que há um receio por parte dos adeptos ao ensino tradicional em utilizar essa ferramenta. Por outro lado, tem-se que o conhecimento adquirido pelos alunos não está apenas restrito à sala de aula, e sim no dia a dia. E é nesse sentido que os jogos podem exercer um importante papel na aprendizagem, visto que pode ser uma estratégia motivadora no ambiente escolar.

Tolomei (2017) mostra os aspectos da gamificação, de modo que nessa temática também são trabalhados pontos como motivação e engajamento, entre outros. Em seu texto é mostrado que a gamificação é uma tendência que surge a partir da popularidade dos jogos, em que suas potencialidades estão na motivação, resolver desafios e recompensa em troca de metas atingidas.

Nessa perspectiva compreende-se por meio desses pontos que a temática pode ser usada para tornar o aluno mais participativo e estimular suas interações em sala de aula. Em seu estudo, a autora mencionou dois exemplos de gamificação na educação: um deles são dois casos da empresa Badgeville, a "Beat the GMAT (BTG)", que é a maior rede social para candidatos da MBA, e outro da Universidade Kaplan. Outros exemplos são dois projetos brasileiros, como o projeto "Logus: a saga do conhecimento" e o projeto "Arkos".

Diante disso, Tolomei (2017) afirma que a gamificação pode ser uma importante aliada que contribui no engajamento e motivação dos alunos em sala de aula, de modo que sua proposta é algo inovador a partir do momento que usa os elementos dos games com o objetivo de fazer com que as atividades de seus participantes sejam mais divertidas, tornando-se uma ferramenta instigante e colaborativa para o processo de ensino e de aprendizagem.

Conforme Griffin (2014) e Busarello et al (2014) o princípio da gamificação é promover a motivação e o comportamento do indivíduo para dinâmica do ato de jogar, utiliza os mesmos elementos que estimula a participação e os desafios nas aprendizagens adquiridas nos jogos, ou seja, utiliza os elementos dos games fora do contexto, para promover ensino dos conteúdos propostos. 
$\mathrm{O}$ artigo "A utilização da gamificação aliada às tecnologias digitais no ensino da matemática: um panorama de pesquisas brasileiras" (Barbosa et al., 2020) foi publicado na revista Prática Docente, e teve como objetivo comprovar a eficácia da gamificação no contexto do ensino da matemática com o uso das Tecnologias Digitais da Informação e Comunicação (TDIC).

Barbosa et al. (2020) iniciam o estudo fazendo uma análise sobre as dificuldades enfrentadas em sala de aula, em que trazem questões como as diferenças, falta de estímulos, desmotivação, forma como a matemática é vivida no dia a dia e como ela é retratada em sala. São colocadas, também, questões como as aulas mecanizadas, as quais têm o professor como único protagonista do processo de ensino e aprendizagem, causando desinteresse por parte dos estudantes no ensino da matemática.

Nessa perspectiva, os autores começam a fazer uma discussão sobre como as TDIC estão presentes nas vidas dos jovens e de que modo elas impactam, também, no ambiente escolar.

[...] ao se utilizar a tecnologia no ambiente escolar o professor se propõe a explorar as vantagens que este recurso pode trazer para a sala de aula, pois ao utilizá-la a seu favor, esta pode servir como uma forma de estimular o aluno ao aprendizado. Apesar de termos um avanço tecnológico, a Educação e a formação de professores no Brasil não seguem o mesmo ritmo, dificultando sua ampla utilização em sala de aula. (Barbosa et al., 2020, pp. 1594).

Os autores trouxeram, também, as potencialidades das TDIC em sala de aula e como as mesmas podem ser benéficas para o ensino. Nessa perspectiva, trazem as seguintes questões: "Como a gamificação, aliada ao uso das TDIC, pode ser utilizada em sala de aula para o ensino de matemática? Como a gamificação com o uso das TDIC pode ajudar no engajamento nas aulas de matemática?" (Barbosa et al., 2020, pp. 1596).

Nessa análise, os autores também mostraram outro importante aspecto do ambiente gamificado, que no caso é a criação de objetivos e regras nesse tipo de atividade. Assim, foram colocadas as dificuldades na implementação da gamificação no ambiente escolar, dentre as quais estão a necessidade da formação para ser usada em sala de aula e a falta de preparo dos profissionais da educação-

Nessa perspectiva, evidencia-se que a gamificação ajuda em conjunto com as TDIC poderá fazer com que o ensino seja mais atrativo, como também trazer a possibilidade de criar diferentes maneiras de estratégias que podem ajudar no processo de aprendizagem da matemática. Os pontos positivos da gamificação foram: motivação na aprendizagem; e facilidade no entendimento dos conteúdos.

As produções ainda mostram como o formato da atividade desempenhada, a utilização de recursos tecnológicos e os desafios impostos podem atuar como elemento de engajamento para os alunos. Esse incentivo ao aprendizado, gerado em decorrência do uso da gamificação em sala, surge a partir de diferentes fatores, como: elementos e mecânicas de jogo, o que envolve sistema de recompensa, níveis, temporizador, narrativa, dentre outros elementos. Esta realidade auxilia no engajamento da matemática, disciplina esta que trabalha com diversos conceitos abstratos. (Barbosa et al., 2020, pp. 1608).

Diante desse estudo, os autores apontam que o uso da gamificação favorece a aprendizagem, visto que utiliza vários elementos. Pôde-se compreender a necessidade de estudar formas de ensino que ajudem no processo educacional da matemática. Desse modo, a utilização da gamificação e dos jogos digitais potencializa a aprendizagem matemática, pois consoante Busarello et al (2014) o uso de jogos ajuda na retenção da atenção do aluno, o que ocasionará uma melhoria na aprendizagem dos discentes. 
O próximo trabalho traz uma pesquisa de campo realizada em uma escola de ensino fundamental. Dessa maneira, diferentemente dos dois trabalhos anteriores, pode-se ter uma visão mais detalhada do ponto de vista dos estudantes sobre as atividades gamificadas.

A dissertação "Gamificação no ensino da matemática: uma experiência no ensino fundamental" (Esquivel, 2017) teve como objetivo compreender o que é a gamificação e os caminhos que ela pode traçar no tocante às suas aplicações na educação matemática do ensino fundamental, utilizando jogos que envolvam os conceitos estudados em uma turma do oitavo ano do ensino básico.

Esquivel (2017) considera a ressignificação do erro um dos pontos mais importantes da gamificação, pois coloca que no ensino tradicional o erro é um dos maiores receios que os estudantes têm em sala de aula. Quando acontece esse tipo de situação o discente tende a ser punido de diferentes formas, como, por exemplo, com perda de pontos. Dessa forma, em uma atividade gamificada o estudante passa a ter mais liberdade para errar e, consequentemente, passa a praticar mais e aprender com seus erros. O autor traz, também, os conceitos de feedback constante, narrativa e os tipos de motivações exploradas pela gamificação.

Dessa maneira, o autor destaca, ainda, que quando os discentes foram indagados sobre os conteúdos matemáticos que perceberam no jogo, alguns citaram a área e a divisão igualitária, comprimento de lados e perímetro das figuras, simetria e porcentagem. Quando foram questionados sobre a dificuldade do jogo nos níveis mais avançados, os estudantes citaram que os erros sucessivos não se deviam à desestimulação ou à desmotivação, visto que para eles os aplicativos têm a possibilidade de recorrer a dicas, também podendo tirar dúvidas com os seus colegas.

Sobre esse fato, Esquivel (2017, pp. 55) ressalta que: “Acreditamos também (ainda que isto não tenha sido citado pelos alunos), que outro motivo importante para esta resposta é o fato de não haver punição para os erros sucessivos - como retroceder níveis, tendo que resolvê-los novamente, por exemplo".

$\mathrm{O}$ autor evidencia que os jogos Slice it e Euclidea proporcionou que os alunos participassem das atividades, interagissem entre si e estimulou o desenvolvimento de trabalhos coletivos na turma observada. O ensino tradicional é resistente aos recursos digitais e se baseia em aulas expositivas, o que torna as aulas desinteressantes para essa geração cada vez mais tecnológica. Assim, o autor acredita que os games podem ajudar nessa questão.

Esquivel (2017) pontua que ao término da atividade foi indagado aos estudantes sobre os pontos positivos e negativos do jogo, os quais responderam: positivo - a substituição da régua e do compasso por ferramentas virtuais; negativo dificuldade de algumas construções. Nessa perspectiva, quando perguntados se o insucesso constante causa desmotivação, os alunos responderam que sim, de modo que o autor afirma que um dos motivos colocados pelos discentes é o fato da dificuldade ser muito grande em alguns níveis e não haver dicas.

Quando perguntados qual método preferiam usar nas aulas de desenho geométrico, quatro alunos responderam que preferem usar somente régua e compasso, dois afirmaram que preferem somente o aplicativo e os demais optam por usarem os dois. $\mathrm{O}$ autor ainda coloca que, apesar das dificuldades mencionadas pelos estudantes, muitos não se sentiram desmotivados e, dessa forma, não haveria nenhuma resistência em usar o Euclidea em sala de aula, porém o mesmo fato se aplica nas horas livres em casa.

Diante disso, Esquivel (2017) ressalta que quando a gamificação é utilizada em sala de aula tende a reunir o desejo natural do ser humano em jogar, as novas tecnologias digitais e a grande vontade que os jovens têm pelos games. O pesquisador ressalta ainda que: "O professor, portanto, deve atuar como um mediador, auxiliando os alunos a lidarem com as dificuldades, estimulando o debate e a troca de informações e conferindo liberdade para a criatividade, curiosidade e novos questionamentos advindos destas" (pp. 61). 
Percebe-se nesse contexto que os elementos constituem as características dos jogos e estão presentes no processo de ensino e aprendizagem dos estudantes, já que a competição, as regras dos jogos, os personagens, o planejamento, criar estratégias diversas são elementos que são conduzidos pelos alunos ao utilizar a gamificação na aprendizagem.

Dessa forma, afirma que esse processo é rico para a sala de aula, pois incentiva a participação ativa dos alunos no processo de ensino, dando importância aos seus conhecimentos já adquiridos, ressignificando o erro. Assim, a gamificação promove constante feedback, trazendo para o professor, dessa maneira, uma visão mais detalhada de cada aluno. O autor também destaca que a implementação de gamificação na sala de aula pelo professor não é algo rápido e simples, ao contrário, é demorado e exige muito esforço em pesquisas teóricas, além de ter que ir atrás de ideias que possam ser inovadoras.

A seguir, apresenta-se a descrição dos principais resultados da última produção científica incluída neste estudo, sendo realizada uma pesquisa sobre a gamificação relacionando-a com a teoria das situações didáticas. Diferentemente dos trabalhos anteriores, $\mathrm{o}$ autor destaca conceitos como motivação e engajamento, entre outros.

A obra "Gamificação e educação matemática: uma reflexão pela óptica da teoria das situações didáticas" (Gomes, 2017) tem como objetivo fazer uma análise sobre a relação entre a gamificação e a teoria das situações didáticas (TSD). O autor, começa a interligar gamificação com a TSD, tendo como referências os pesquisadores Kapp (2012) e Brousseau (1996), respectivamente, em que os elementos usados para a gamificação foram os objetivos, regrar, tempo, conflito, competição, cooperação, feedback, nível de dificuldade, abstração da realidade e criação de história

Gomes (2017) discorre sobre os objetivos em uma atividade, em que utiliza, os conceitos de Karl Kapp, sobre gamificação, afirmando que os jogos digitais contemplam diversas estratégias e poderão proporcionar maior autonomia e liberdade para o jogador para implementar a ferramenta que ele acha mais eficiente. Com os objetivos em um jogo, traz foco e resultados para a pessoa que está jogando.

Gomes (2017), afirma ainda, que conforme Brousseau, que o professor deve levar em conta situações que faça com que os alunos aceitem os desafios de solucioná-los para que, assim, questione-se acerca de suas próprias escolhas. É dito, também, que através do jogo se pode ver o objetivo, criando, assim, ideias para solucioná-lo. Essas atividades procuram abordar situações que os alunos pesquisarão soluções, métodos de resolver as atividades propostas.

Verificamos, que as regras em uma atividade nas TSD estão relacionadas com o contrato didático que tem uma relação com a prática do jogo. Gomes (2017, pp. 71) afirma que: "Portanto, observamos que tanto na gamificação como na TSD as regras possuem um papel fundamental para estruturação da atividade desenvolvida com os alunos".

Nessa perspectiva, Gomes (2017) traz o conceito de tempo, e coloca que, de acordo com as TSD, se o professor não proporciona tempo necessário para os alunos fazerem uma atividade, o milieu ${ }^{6}$ não vai se estruturar de forma adequada, o professor vai dar informações em excesso ou, até mesmo, dar resposta ao ser questionado. Com isso, o autor afirma que na TSD e na gamificação o tempo é um dos elementos mais importantes no seu processo, também colocando que o tempo reservado para a realização das atividades dos trabalhos selecionados foi bem escasso.

O autor destaca também os seguintes elementos verificados na utilização dos jogos em sala de aula: o sujeito deve redobrar sua atenção no jogo para que, assim, possa melhorar sua performance; os indivíduos vão trabalhar juntos com a intenção de atingir seus objetivos, onde muitas vezes é desenvolvida uma solução para o problema de maneira cooperativa; a possibilidade de ser abordado o elemento feedback, que ele traz para o jogador uma análise de seu desempenho na atividade; criação de níveis de dificuldades, ou seja, deve-se estar atendo ao nível de dificuldade da atividade e ao nível do jogador, pois ambos devem ser proposicionais.

\footnotetext{
${ }^{6}$ Em sua pesquisa, Gomes (2017) opta por usar o termo milieu em francês. Traduzido no português, esse termo significa "meio", assim ele coloca que ele não possui todas as ideias presentes no milieu. Desse modo, o autor coloca que, para Brousseau, milieu é uma estratégia que não tem intenção didática, externa ao indivíduo, em que vai permitir que o estudante faça uma reflexão sobre suas ações e aprendizagem quando recuar e verificar suas ações.
} 
Além disso, alguns jogos utilizam conceitos históricos, contextos sociais que incentivam a capacidade de captar a realidade, isso pode ser algo positivo. Nesse ponto, o autor afirma que a situação do jogo tende a se assemelhar muito à situação da vida, como ação, emoções, motivação e divergências. Nesse sentido, Gomes (2017, pp. 83) coloca que:

Em vista disso, evidenciamos que a abstração da realidade ocorre com uma mudança de ambiente ou não. Entretanto, o que realmente é importante, não é qual, mas, sim, como a abstração da realidade pode auxiliar na construção de uma situação, que pleiteie dar condições aos alunos a aprender e compreender o novo saber matemático. (Gomes, 2017, pp. 83).

Desse modo, o autor coloca que a criação de história tem como objetivo envolver o aluno em um desafio e em uma situação-problema para que, assim, o indivíduo resolva a atividade. Assim, Gomes (2017) destaca que há necessidade de realização de trabalhos e eventos que abordem a gamificação em sala de aula, como também uma articulação entre os professores e os desenvolvedores dos jogos. Também é colocado que deve ser feita uma relação da gamificação com outras teorias da educação para que, assim, ela tenha potencializada suas estratégias didáticas. Ainda, que os elementos da gamificação estão presentes em uma interação didática estruturada pela dialética da ação, formulação e validação.

Perante os trabalhos analisados, evidencia-se que os autores se encontram em muitos pontos, como, por exemplo, a motivação e o engajamento que a gamificação causam nos alunos. Ainda, os autores compartilham seus apontamentos sobre o ensino tradicional, pois colocam em seus estudos que a forma como a matemática é abordada por essa metodologia causa desmotivação do aluno em sala de aula.

Griffin (2014), Busarello et al (2014) e Filatro (2008) descrevem ainda a necessidade de um planejamento bem delineado para que os docentes possam conhecer os mecanismos dos jogos e as relações que os alunos irão exercer sobre eles, não é suficiente apenas romper o ensino tradicional, mas também buscar caminhos que possam dialogar com todas as áreas do conhecimento e saber conduzir esse processo como uma atividade de ensino.

Kenki (2013) ainda aponta em suas pesquisas que o uso da tecnologia necessita de profissionais que estejam disposto a adquirir as habilidades necessários para o uso dos equipamentos tecnológicos ligados aos conhecimentos atuais, além disso relacionar as práticas pedagógicas para adequar as novas gerações de estudantes, os identificados por Prensky (2012) como nativos digitais, que já nasceram imersos nessa cultura digital.

Os pesquisadores Mozer e Nantes (2019) corroboram que a gamificação poderá ser utilizada nas aulas, como recurso de informação, tendo o objetivo de estimular o processo de ensino e aprendizagem, além de desenvolver a autonomia dos alunos, com o uso de softwares específicos, para analisar as tarefas que auxiliem nas aulas e possam contribuir na aprendizagem dos conteúdos específicos.

\section{Considerações Finais}

Este trabalho que teve como objetivo discutir o processo de gamificação e suas contribuições no ensino de matemática, destaca o quão importante é o professor planejar de forma que possa contemplar diversas propostas de atividades que incentivem os alunos a interagir, participar ativamente das propostas de trabalho desenvolvidas pelo docente, além de desenvolver o aspecto de interação, busca pela resolução de problemas individuais e/ou de forma coletiva com os colegas de sala.

Nessa perspectiva, a gamificação no ensino da matemática apresenta muitas potencialidades e contribuições no processo de aprendizagem. Os elementos presentes nela fazem com que os estudantes se sintam mais contemplados e motivados a aprender. Assim, conclui-se que a gamificação pode atender às questões apontadas no início deste estudo, pois os elementos que deseja empregar fazem parte do dia a dia de muitas crianças e adolescentes. 
Diante disso, acredita-se na importância que a gamificação representa ao ensino da matemática e aos outros componentes curriculares, pois seus benefícios podem contribuir ainda mais na qualidade da educação de modo geral. Nessa perspectiva, torna-se enriquecedor relacionar a gamificação com outras teorias da educação ou metodologias de ensino, pois os elementos presentes nela podem ser, ainda, mais explorados em sala de aula.

Destaca-se o quão importante é instigar ideias de ensino que possam contribuir para que o discente seja protagonista de seu próprio processo de ensino e de aprendizagem. O professor pode ser o mediador do conhecimento adquirido pelo sujeito. Acredita-se, que a comunidade escolar (docentes e gestores) necessita contemplar modelos de ensino que exploram a realidade do dia a dia dos estudantes, buscando adaptações para essas questões.

Mas, para que isso seja feito, precisa acontecer outro ponto importante: é necessário que a gamificação seja mais estudada e aplicada em sala de aula, seja pelos professores ou por pesquisadores, pois apesar de ter muito potencial, a gamificação no ensino da matemática ainda pode evoluir mais e trazer maiores benefícios para a educação, necessitando ser explorada em todas as suas potencialidades para alcançar resultados ainda mais eficientes para a comunidade acadêmica e nas escolas da Educação Básica.

Por fim, apesar da gamificação apresentar os fatores positivos apontados no decorrer do texto, ressalta-se que quando aplicada na educação, fica claro que não há uma certeza de que as escolas do ensino básico tenham uma estrutura adequada para implementação dessa estratégia. Isso fica ainda mais evidente quando se olha em relação às escolas públicas no Brasil, pois têm-se como outra grande dificuldade a recepção dos professores em relação à utilização dessa forma de ensino na sala aula, uma vez que muitos ainda são adeptos ao ensino tradicional e, consequentemente, são resistentes a novas ideias de ensino que podem ser usadas no ensino da matemática.

\section{Agradecimentos}

O presente trabalho foi realizado com apoio da Coordenação de Aperfeiçoamento de Pessoal de Nível Superior Brasil (CAPES) - Código de financiamento 001, programa de Pós-Graduação em Ensino - PPGEnsino da Universidade do Vale do Taquari - Univates.

\section{Referências}

Alves, F. (2015) Gamification - como criar experiências de aprendizagem engajadoras. Um guia completo: do conceito à prática. (2a ed.), DVS.

Avila, L. A. B. et al. (2017). A interdisciplinaridade na escola: dificuldades e desafios no ensino de ciências e matemática. Revista Signos, $38(1)$, 9-23.

Barbosa, F. E., Pontes, M. M., \& Castro, J. B. (2020). A utilização da gamificação aliada às tecnologias digitais no ensino da matemática: um panorama de pesquisas brasileiras. Revista Prática Docente (RPD). Confresa, 5(3), 1593-1611.

Brosseau, G. (1996). “Fundamentos e métodos da didática da matemática”. In: Brun, J. Didática das matemáticas. Tradução de Maria José Figueiredo. Lisboa: Instituto Piaget, p. 35-113.

Busarello, R. I. et al. (2014). A gamificação e a sistemática de jogo. In: Fadel, L. M. et al. (Org.). Gamificação na educação. Pimenta Cultural.

Esquivel, H. C. da R. (2017). Gamificação no ensino da matemática: uma experiência no ensino fundamental. Dissertação de Mestrado - Curso de Matemática, Universidade Federal Rural do Rio de Janeiro, Seropédica.

Fardo, M. L. (2013). A Gamificação como estratégia pedagógica: Estudo de elementos dos games aplicados em processos de ensino. 2013. Dissertação de Mestrado - Curso de Educação, Universidade de Caxias do Sul, Caxias do Sul.

Filatro, A. (2008). Design instrucional na prática. Pearson.

Gee, J. P. (2009). Bons videogames e boa aprendizagem. Revista Perspectiva, 2791), 167-178.

Gomes, M. S. (2017). Gamificação e Educação Matemática: uma reflexão pela ótica das teorias das situações didáticas. Dissertação de Mestrado - Curso de Educação Matemática, Pontifícia Universidade Católica, São Paulo.

Griffin, D. (2014). Gamification in E-Learning. Ashridge Business School. http://www.ashridge.org.uk/Website/Content.nsf/wELNVLR/Resources:+Gamification+in+e-Learning?opendocument. 
Research, Society and Development, v. 11, n. 1, e7811124613, 2022

(CC BY 4.0) | ISSN 2525-3409 | DOI: http://dx.doi.org/10.33448/rsd-v11i1.24613

McGonical, J. (2012). A realidade em jogo - por que os games nos tornam melhores e como eles podem mudar o mundo. Trad. Eduardo Rieche. Best Seller.

Mozer, M., \& Nantes, E. A. S. (2019). Gamificação no Ensino de Matemática: das Diretrizes Curriculares do Paraná à sala de aula, via Plano de Trabalho Docente. Research, Society and Development, 8(4), e4584883. https://doi.org/10.33448/rsd-v8i4.883

Prensky, M. (2012). Aprendizagem baseada em jogos digitais. Senac.

Kapp, K. M. (2012). The Gamification of Learning and Instruction: Game-based Methods and Strategies for Training and Education.

Kenski, V. M. (2003). Tecnologias e ensino presencial e a distância. Papirus.

Santos, A. C. \& Magedanz, A. (2018). Metodologias ativas e qualificação docente: Um estudo de caso. Revista Signos, 39(2), 56-71.

Sousa, F. G. M., Erdmann, A. L. \& Magalhães, A. L. P. (2019). Capítulo 4 - Contornos conceituais e estruturais da pesquisa qualitativa. In: Lacerda, M. R, Constenaro, R. G. S. Metodologia da pesquisa para a enfermagem e saúde: da teoria à prática. Moriá.

Tomelei, B. V. (2017). V. A Gamificação como Estratégia de Engajamento e Motivação na Educação. Ead em Foco, 7(02).

Zichermann, G. \& Linder, J. (2013). The gamification Revolution how leaders leverage game mechanics to crush the competition. The McGraw-Hill Companies, Inc.

Zichermann, G. \& Cunningham C. (2013). Gamification by Design: Implementing Game Mechanics in Web and Mobile Apps. O'Reilly. 